\title{
Marquesa Casati, un caso de idolatría*
}

\author{
Jorge LOZANO \\ Universidad Complutense de Madrid
}

(Abstracts y palabras clave al final del artículo)

Cuando se habla de dandi o de dandismo habitualmente se declina en masculino: Brummell, Čaadaev o, en la literatura, Pelham, tal y como lo describe BulwerLytton. Caso de que se hablare del dandismo en femenino, sin duda alguna aparecería el nombre de la Marquesa Casati. Se trata en su caso de mucho más que una plausible analogía con una forma de vida, con la pose. Mucho más que una cierta afinidad con el estilo dandi. Ella, que había introducido con su conocidísima proclama (voglio essere un'opera di arte vivente) la relación entre arte y vida, como ya había hecho otro dandi, Oscar Wilde, o que, parafraseando el Sartor resartus de Thomas Carlyle, mientras el resto del mundo dress to live, ella lives to dress.

No en vano, el grado de comparación entre la Marquesa Casati y Moda es altísimo, si aceptamos el rol para ambos personajes de la iniciativa dinámica hacia la novedad, hacia la extravagancia. Si la moda es la visible encarnación de la novedad inmotivada o el dominio de caprichos monstruosos y, al mismo tiempo, esfera de creatividad innovativa, tanto la moda como la Marquesa Casati se sitúan en los confines de lo lícito, más allá de los límites de la previsibilidad.

Luisa Casati fue de las primeras que compró un Delphos ${ }^{1}$ —el vestido-icono creado por Mariano Fortuny - y con Ida Rubinstein, bailarina de los ballets rusos, fue la cliente más importante de Paul Poiret, que no solo la vistió en tantas ocasiones, sino que creó un vestido de estofa metálica color plata para su doble: una estatua que la Marquesa sentaba a la mesa junto a sus comensales. Y aún el conocido vestidofuente o "los vestidos macabros fúnebres" que le merecieron el sobrenombre de

\footnotetext{
* Este artículo apareció en italiano en el catálogo La divina Marchesa. Arte e vita di Luisa Casati dalla Belle Époque agli anni folli editado por 24 ore cultura (pp.231-241) con motivo de la exposición que se hizo en el Museo Fortuny de Venecia (4 oct 2014- 8 marzo 2015). Agradezco a Daniela Ferretti, directora del Palacio Fortuny, que me solicitó y autorizó la publicación de este texto.

${ }^{1}$ Agradezco especialmente a Claudio Franzini, cuyas investigaciones han permitido atestiguar la adquisición por parte de la Casati del hábito Delphos de Mariano Fortuny. Gracias a su amable concesión, cito la referencia bibliográfica completa: Biblioteca Nazionale Marciana, Fondo Mariutti Fortuny. Carteggi, minute e miscellanea. Scatola M. 5 M. 5.2.2. Quaderno registro vendite di abiti dal 6 al 28 settembre 1909. Alla data: 28091909 Marchesa Casati 1 Delphos imprimé et plisse en soie de chine 300 Fr.
} 
Venus del Père La-Chaise, el cementerio parisino que el historiador Michelet podía ver todos los días desde su casa, escenario de sus habituales paseos, y del que llegó a decir algunos años después: "J'aime la mort, j'ai vu le sang noir des morts". Y en París, Luisa Casati paseaba con un vestido de terciopelo negro de Madeleine Viollet.

Y también Léon Bakst, celebérrimo figurinista de los ballets rusos creó para ella vestidos como La reina de la noche, de 1922, vestido de gran pompa, en italiano sfarzo. La palabra sfarzo", en su étimo, contiene la máscara, el disfraz, que tanto gustaba tanto a la Marquesa como a Fortuny: recordemos a este último con chilaba y turbante y a la Marquesa disfrazada como condesa de Castiglione.

En tantas imágenes, de hecho, Luisa Casati aparece camuflada, disfrazada. Organizadora de tantos bailes, máscara de ella misma. Más allá de Venecia y de tantos cuadros de Pietro Longhi, vale la pena detenerse brevemente sobre este importante objeto. Podemos comenzar diciendo que una máscara es un signo que simultáneamente muestra y oculta. Y que, como signo, es al mismo tiempo transparente y opaco. Según Canetti (1960), "la máscara se distingue por su rigidez de todas las demás fases finales de la metamorfosis". Y añade: "detrás de la máscara comienza el misterio". Y añado: por ello se sospecha y se teme detrás de ella lo ignoto.

Me permito recordar en este punto cómo en la biografía o leyenda de la Marquesa estaban incluidos entre sus iconos Ludwig II de Baviera, Sarah Bernhardt y la Condesa de Castiglione. ¿Qué pretende la Marquise? ¿Imitar? ¿Evocar? ¿Reproducir? ¿Mimetizar? Lo que es cierto es el efecto que provoca sobre los espectadores: con su presencia a veces perturbadora, suscita siempre impresión y estupor: "Medusa o tigre que sea, cuando sonríe parece que muerda", parece que dijo de ella Robert de Montesquiou.

Es una presencia escénica, dramática, un "efecto dramatúrgico", diría Goffman, que explica que el self es una construcción y no un dato previo, resultado de una interacción, de una representación en sentido teatral. Y recurriendo una vez más al étimo, no podemos no decir que el término persona, derivando del latín 'persona', al inicio indicaba la máscara (en griego, prosopon que, a su vez, designaba el rostro en estrecha relación con la mirada). Jugando como se debe con la etimología, que es una forma de retórica, una derivación de la palabra "persona" conduce también a Persu, divinidad etrusca del mundo de los infiernos. Y siempre, para permanecer en el étimo mitológico, aunque algunos lo colocan en Perseo, el rasgo distintivo, aquello que fundamentalmente permanece, es la máscara. Prosiguiendo con la construcción de esta palinodia que vamos configurando, el personaje de Luisa Casati se delinea por el hecho de estar a menudo acompañado de un repertorio de animales: los famosos lebreles (Giovanni Boldini), los papagayos (Lulo de Blaas), las serpientes (Alberto Martini), las blancas siluetas de caballos (Man Ray).

Guepardo, leopardo, león, tigre: todos términos que en la Grecia antigua designaban al género de la pantera. Es un universo de fieras denso de significado simbólico y mitológico, estrechamente ligado al mundo de la Marquesa, que como testifican tantas fotografías y tantos cuadros, no solo amaba portar pieles, sino que tenía consigo algunos guepardos, uno de los cuales, como cuenta la misma bailarina en su biografía, aterrorizó mucho a Isadora Duncan.

Luisa Casati podría considerarse como una nueva Artemisa, señora de las fieras, o "aquella que ama a los animales", pero también divinidad de los márgenes, que 
generan el sentido de la frontera entre el mundo salvaje y el mundo civilizado. Parece, además, que en la mitología griega la pantera poseyera la peculiar capacidad de la frónesis, una prudencia mezclada con la astucia, entendida como inteligencia que sabe simular y que oculta los objetivos que se propone. Como cuenta Marcel Detienne (La panthère parfumée, 1946), ella es el único animal no maloliente, sino que, al contrario, exhala un olor cautivador, un perfume que utiliza para atraer a sus presas. De ahí la costumbre de llamar pantera a las cortesanas en general, que encuentra un antecedente en Aristófanes, y más concretamente en Lisístrata. Vale la pena detenerse en una figurativización de Luisa Casati obra de Erté, diseñador de moda, figurinista, escenógrafo y firma de la revista Harper's Bazaar. El poliédrico artista, asistente de Paul Poiret (firmaba Erté, traducción fonética del francés R.T., iniciales de Romain de Tirtoff), crea su famoso e inolvidable alfabeto de veintiséis letras con un sofisticadísimo trabajo de siluetas, donde pone en relación mujer y letra, convirtiendo a la primera en signo, en una cifra. Erté elige a la Marquesa Casati para configurar, con admirable estilización la letra L.

"L" como Leopardo, como "lien et liane" (Roland Barthes), donde una abstracción sutil, casi una línea vertical (la Marquesa) está ligada a un leopardo, a una pantera (la línea horizontal). Demasiado fácil: lo hace también Barthes. Cómo no pensar en la mujer pantera, en la pardalis, felina y perfumada.

Otro animal clave es la serpiente, que adorna el sutil cuerpo envolviéndolo con reptiles vivos enredados alrededor del cuello, casi incorporados a su figura. Una de sus boas constrictors se llamaba Anaxágarus; Cocteau se refirió a ella como "le beau serpent du paradis terrestre". Sin duda, la serpiente es un animal sumamente inquietante, además de ser símbolo universal. En El ritual de la serpiente, Aby Warburg sostiene que en el culto orgiástico de Dionisos las ménades danzaban con una serpiente viva envuelta alrededor de la cabeza como si fuera una diadema, llevando en una mano culebras y tirando con la otra de la correa al animal que después sería degollado en honor al dios en el curso de la ascética danza sacrifical.

Queremos resaltar la idea fascinante de Warburg sobre la ambigüedad, la duplicidad, la doblez del significado simbólico de la serpiente que nuestro autor sintetizaba en los dos magníficos de Laocoonte y Asclepio. Una polaridad del símbolo en el que, por una parte, la estatua de Laocoonte extrae la quintaesencia del dolor en la muerte, la agonía, el agón, la lucha; y, por otra parte, Asclepio, señor de las serpientes y divinidad astral hace un fármaco, una terapia, una cura, una resurrección.

La serpiente es también la máscara bajo la cual se agita el demonio, aquel diablo tal y como aparece por primera vez a los humanos en el jardín del Edén. Una perfecta combinación para Luisa, o como la llamaba el vate, para Coré, Perséfone temible por su mirada aterradora.

Una mirada reproducida de muchas maneras por tantos artistas distintos para los cuales posó: ojos inmóviles como de esmalte (Alberto Martini), ojos de mica (Giacomo Balla). Ojos exageradamente brillantes gracias a las gotas de belladona. Entre el único ojo egipcio de algunos cuadros de Kees Van Dongen - "un oeil naissant couvert par ses paupières", por decirlo con Nerval-y varios pares de ojos, efecto del azar o de un error, en la famosa fotografía de Man Ray, definida por el mismo artista como "versión surrealista de la Medusa", están los ojos fijos en la obra 
de Ignacio Zuloaga, en un paisaje inequívocamente español, con los molinos de viento, alusión a Don Quijote y a la Maja desnuda de Goya en el abanico que la Marquesa tiene en la mano justo en el centro del cuadro. Si hay algo que produce estupor verdaderamente es el elemento discursivo de la frontalidad, de dos ojos exageradamente pintados y de la mirada petrificante que no puede no conducirnos a la representación de la Gorgona, único personaje que, en la pintura vascular griega, está permitido lícitamente de mirar a la cara del espectador, provocándole así aquellos efectos nefastos o pasionales bien conocidos.

En el interior de la semiosfera de la divina Marquesa encontramos serpientes: ¿Casati diabolique? Panteras, guepardos, leones: ¿Casati lionne? La mirada aterradora como Gorgona: ¿Casati Medusa?

Tras estas referencias iconográficas y personajes de su vida, ahora podemos volver a la moda. Diosa de las apariencias. Atracción formal del límite: la moda debe siempre al principio escandalizar. Después, y ello sucede siempre, debe ser aceptada y seguida. He aquí su ley: un diktat que prescribe que ninguno pueda huir, y aquí radica también la extrema diferencia con el dandismo. Emblema del individualismo, excéntrico en todos los sentidos, extraño, siempre imprevisible, el dandismo no tolera el mínimo rastro de vulgaridad. Contra la vulgaridad lleva una lucha implacable. Mantiene una intensa tensión, acercando los opuestos, los contrarios, el ser y la apariencia. El dandi funde y confunde estas dos categorías semánticas; solamente así se comprende que nunca jamás lleve un vestido nuevo o por qué Brummell, según la leyenda, pidiese a su mayordomo Robinson que se sentara sobre su chaqueta para arrugarla. El dandi Brummell no puede soportar que alguien, en vez de mirarle a él, se fije en su chaqueta o en su vestido, no acepta que prevalezca la apariencia; es más, quiere que la apariencia y el ser se confundan y se identifiquen. Ebrio sobre todo de distinción, la perfección en el vestir consiste en la simplicidad absoluta, que es en efecto el mejor modo de distinguirse, como decía del dandi Baudelaire. La Marquesa Casati puede coincidir y coincide con el dandi, por ejemplo, en la capacidad de estupor, en la imprevisibilidad, en el elevado grado de excentricidad, comparable al rechazo de cualquier forma de vulgaridad. Pero no comparte con la gramática del dandi el estoicismo que lo lleva, lo hemos dicho, a la simplicidad absoluta. Si es verdad que Brummell haya afirmado que "para ser elegante no es necesario hacerse notar", no parece que un semejante dictum se pueda aplicar con rigor a la Marquesa Casati. El dandi es como el falsificador de obras, conoce a la perfección la historia del arte para poder proceder a su falsificación, sabe perfectamente cuáles son las reglas que después modifica, altera o de las cuales se burla.

Por estos motivos y en manera específicamente semiótica, me permito incluirlo en lo que Yuri Lotman ha definido cultura gramaticalizada, distinguiéndola de la cultura textualizada. Muy brevemente la primera es una cultura que, basándose precisamente sobre la gramática, está hipercodificada (como puede serlo, por ejemplo, el código romano que, basado sobre el silogismo "si a, entonces b", sanciona toda acción). La cultura textualizada está, en cambio, hipocodificada, no hace uso de la gramática, sino del texto, del ejemplo (para mantenernos en el ámbito jurídico, podemos referirla al sistema de la Common Law, basada sobre la aplicación no de una norma codificada, sino del principio "en caso análogo, sanción análoga"). Mientras la primera es una cultura orientada hacia el contenido, la segunda tiende hacia la expresión. 
Y entonces se podría decir que el dandi pertenece tout court a la cultura gramaticalizada y que, a su vez, esta sirve de ejemplo para todos aquellos que, imitándolo, formen parte de la cultura textualizada, precisamente como la figura de Luisa Casati.

Así en el universo expresivo de la Marquesa merece añadir alguna palabra la precedente referencia a la estatua, su réplica perfecta que ponía en la mesa al lado de sus invitados. Una fascinación por parte de la Marquesa por las copias y en modo particular por las copias humanas que la llevó a mandar realizar un calco perfecto de sí misma. Un perfecto doble de cera, una gemela en parafina, adornada y vestida como ella. También aquí otra singular actividad: es una constructora de eidola, estatuas, imágenes, colosos, simulacros, dobles, gemelos.

¿Narcisa, o variación singular de Pigmalión donde ella es también Galatea? Podemos quizás extraer el sentido en las palabras de figures de cire de D'Annunzio: "no tengo miedo - cuando estrangulo a Coré, la estatua de cera está allí. Identidad de cadáver y estatua siempre sentada y vestida del mismo modo. De repente la estatua se alza. Está viva, como si el último respiro de la mujer muerta fuese pasado a su terrible simulacro" (traducción nuestra). Y podemos también ir más allá en la consideración de la cena con su doble sentado en la mesa al lado de sus pasmados huéspedes. Quisiera aquí denominar tal actuación de la Casati una performance. Por tanto, si en una lista imaginaria (pero no tanto) encontrásemos el nombre de Luisa Casati junto a nombres como Yves Klein, Vito Acconci, Chris Burden y Marina Abramovich, nadie se sorprendería de verla incluida entre estos célebres performance artists. Al menos se hallaría de manera inequívoca un cierto aire de familia. El mismo que nos permite reconocer inmediatamente el sello de la Marquesa en las más recientes referencias de Tilda Swinton o Marisa Berelson, o en los vestidos de John Galliano, Alexander McQueen o Karl Lagerfeld. Todos clarísimos ejemplos de una cultura textualizada en la que la Marquesa es icono. Todas ellas magníficas creaciones que, más allá de gramáticas rígidas o reglas hipercodificadas, toman como ejemplo, como texto y como icono a Luisa Casati. La misma mujer de la foto expresionista de Cecil Beaton. La última.

Casi espectral, representación de una irritada y sorprendida Madama Morte, hermana de Madama Moda, ambas hijas de la Caducidad. Se trata de una fotografía en la que la Marquesa trata de cubrir con un gesto el mismo velo que oculta los ojos, incluso la propia máscara desnuda. Se esconde en un raptus o secuestro, en su decadencia puede aparecer solo el ocaso, sin calor, lleno de melancolía. Pecio, resto, ruina, espectro de la excéntrica, excepcional, excesiva, excelsa Marquesa.

Ocultando la propia ocultación, simulando la velada simulación, se niega; ella, que posó para tantos pintores, escultores y fotógrafos, muestra y demuestra que ya no quiere ser vista. No quiere mostrar, ni demostrar, no pide nada.

Y muere víctima de sus propios ojos (Ovidio). Quería ser, lo ha sido, una obra de arte viva. Ídolo, icono, performance artist, protagonista de anacrónica silver folk novel.

$\mathrm{Y}$, en fin, ¿podemos decir que fue una dandi? Debemos esperar que la Marquesa Casati, como Juana de Arco, encuentre su Michelet.

Por el momento, decimos "forse che sì, forse che no". 


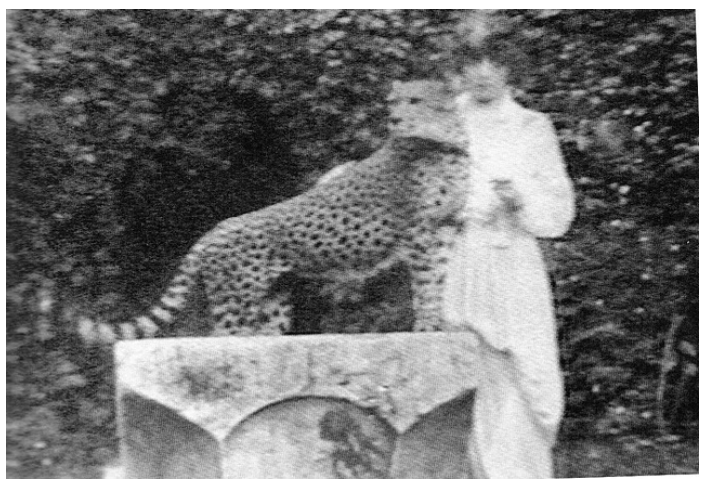

Fig.1.Luisa Casati con su cheetah, Venecia, fotógrafo desconocido, ca.1912.

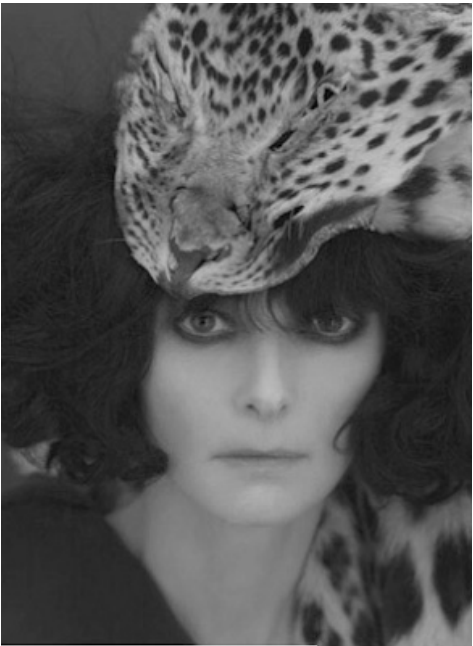

Fig. 2. Tilda Swinton. Fotografía de Paolo Roversi.

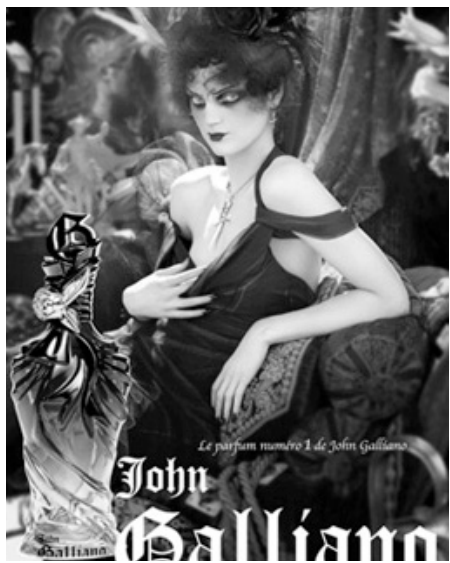

Fig. 4. John Galliano para Christian Dior Couture.

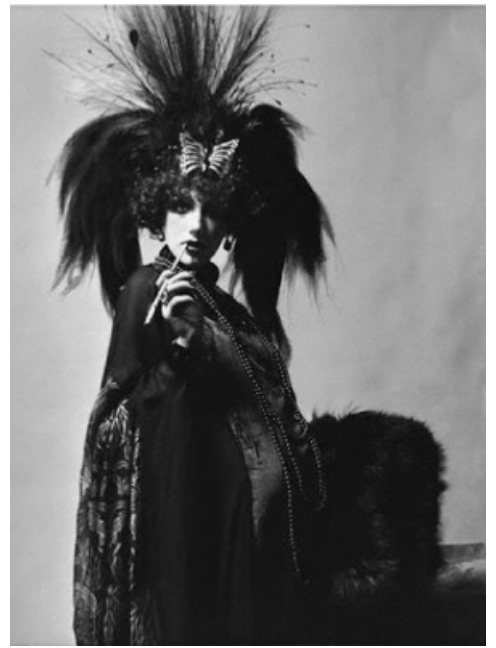

Fig. 3. Marisa Berenson vestida como la Marquesa para Rothschild Ball, 1972.

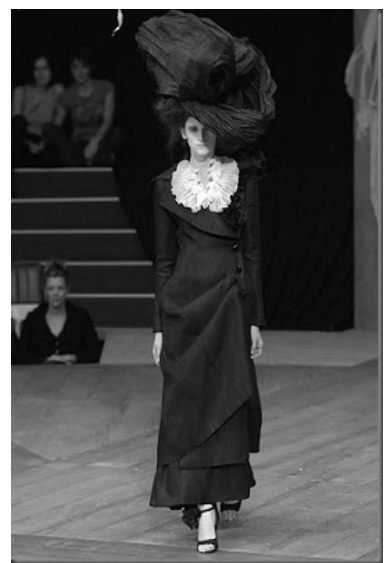

Fig. 5. Alexander McQueen. 


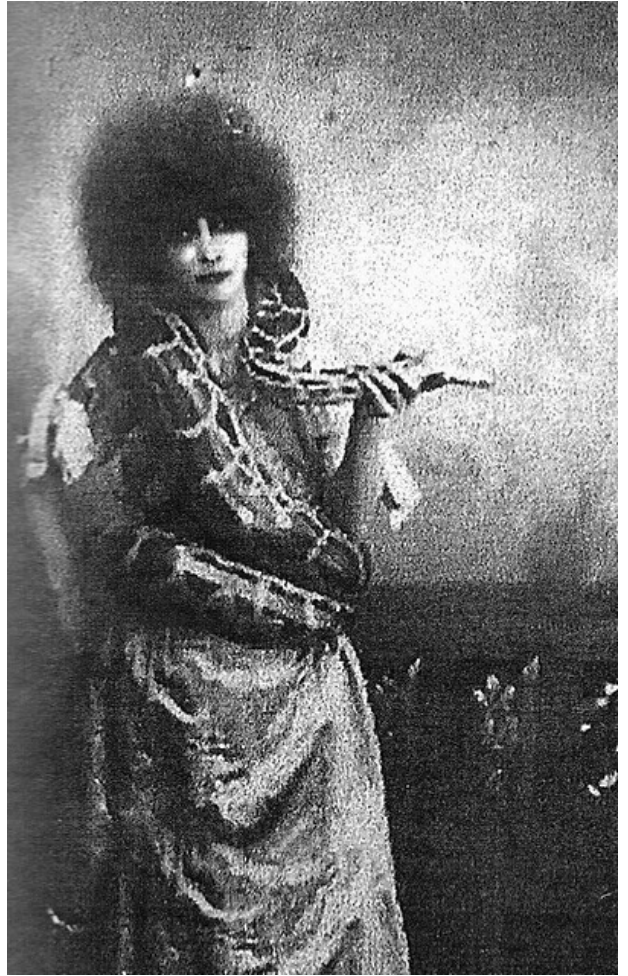

Fig. 6. Luisa con su serpiente en Beaumont ball, Paris, años 20

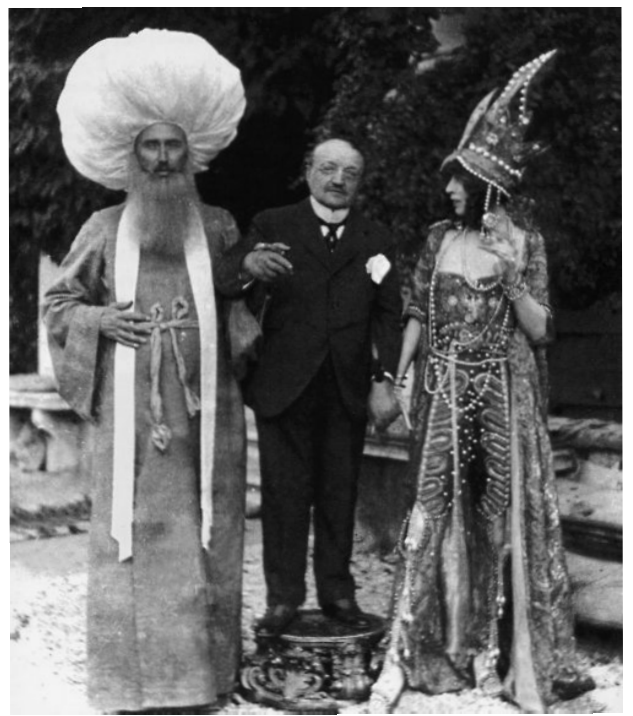

Fig. 8. Paul-Cèsar Helleu, G. Boldini y L. Casati vistiendo el vestido Indio-persa en el jardín del Palacio de Leoni, fotografía de Mariano Fortuny,1913.

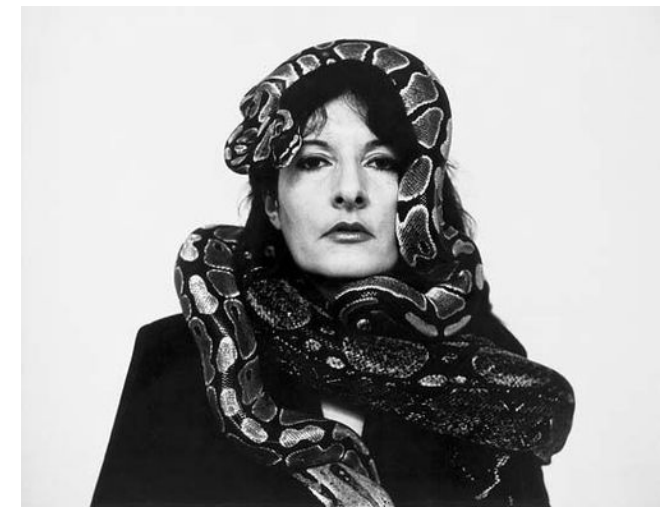

Fig. 7. Marina Abramovic, Dragon Heads performance, vídeo, 1993.

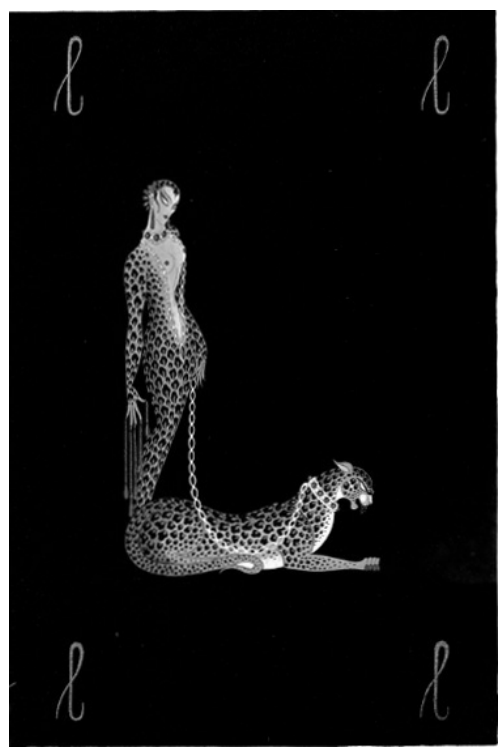

Fig. 9. Erté, «L». 


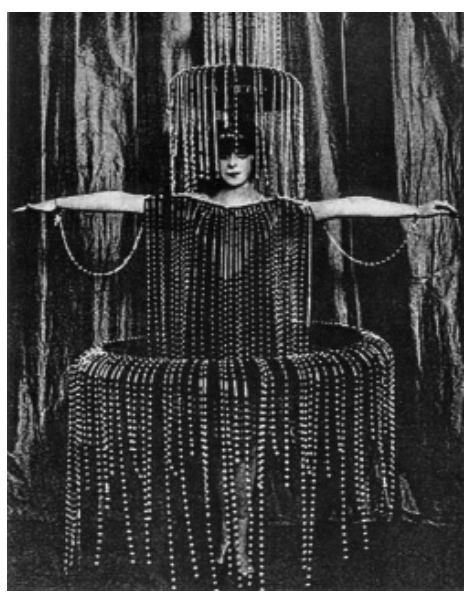

Fig. 10. Luisa en un vestido-fuente diseñado por Poiret, 1920.

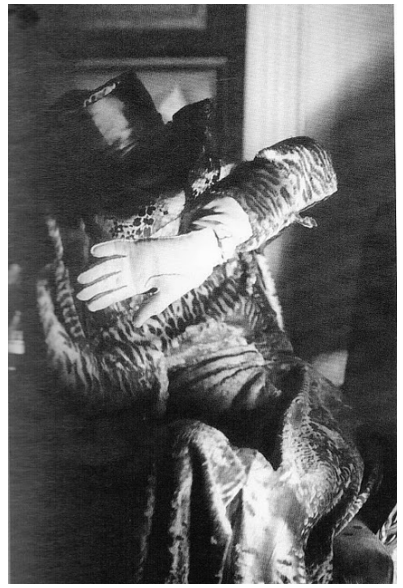

Fig. 11. Luisa Casati por Cecil Beaton, 1954.

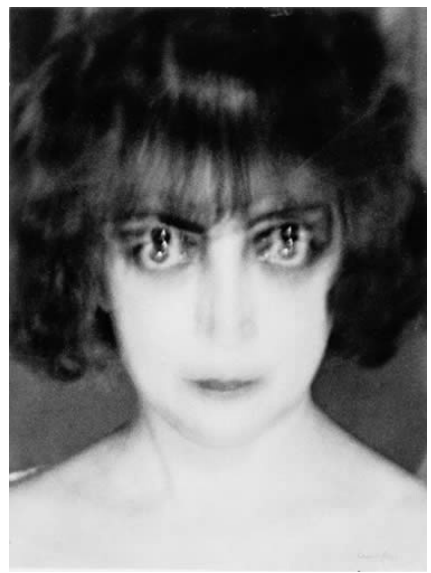

Fig. 12. Man Ray, 1922. 


\section{BIBLIOGRAFÍA}

CAnetti, Elias (1960), Masa y poder, Alianza, Madrid 2009, pp. 441-442.

DETIENNE, Marcel (1976), La panthère parfumée, Univerità di Urbino, Urbino.

GOFFMAN, Erving (1959), La presentación de la persona en la vida cotidiana, Buenos Aires, Amorrortu 1993.

LozAno, Jorge, ed., (1979), Semiótica de la cultura. Jurij M. Lotman y la Escuela de Tartu, Cátedra, Madrid.

WARBURG, Aby (1988), El ritual de la serpiente, Sexto Piso, Madrid 2008.

\section{RESUMEN}

Reflexión semiótica sobre la figura de la marquesa Casati.

Palabras clave: Marquesa Casati, semiótica, dandismo, mujer.

\section{Marquise Casati, a Case of Idolatry}

\section{ABSTRACT}

Semiotical reflection upon the figure of Marquese Casati.

Keywords: Marquese Casati, semiotics, dandism, woman.

\section{RÉSUMÉ}

Reflexion sémiotique sûr la Marquise Casati.

Mots-clé: Marquise Casati, sémiologie, dandisme, femme. 